\title{
PROFESSIONAL AND SOCIAL ACTIVITY OF PATIENTS AFTER HEART TRANSPLANT
}

\section{URSZULA MARCINKOWSKA ${ }^{1}$, KAROL KUKOWKA ${ }^{1}$, MICHAŁ GAŁECZKA ${ }^{1}$, ROBERT PUDLO ${ }^{2}$, MICHAŁ ZAKLICZYŃSKI ${ }^{3}$, and MARIAN ZEMBALA ${ }^{3}$}

${ }^{1}$ Medical University of Silesia in Katowice, Zabrze, Poland

School of Medicine with the Division of Dentistry in Zabrze

Chair and Department of Medicine and Environmental Epidemiology

${ }^{2}$ Medical University of Silesia in Katowice, Tarnowskie Góry, Poland

School of Medicine with the Division of Dentistry in Zabrze

Chair and Clinical Ward of Psychiatry

${ }^{3}$ Silesian Centre for Heart Disease, Zabrze, Poland

Chair and Clinical Department of Cardiac Surgery and Transplantology

\begin{abstract}
Objectives: The aim of the study is to describe both professional and social activities of patients after heart transplant. Material and Methods: Ninety-five heart transplant patients treated at the Silesian Center for Heart Diseases in Zabrze were surveyed, comprising 29 women (30.5\%) and 66 men (69.5\%). The average age of respondents was 54.3 years old (standard deviation $(\mathrm{SD})=15$ years); the average period that had elapsed since the heart transplant was 7.1 years $(\mathrm{SD}=4$ years). We designed a questionnaire as a tool for collecting information from patients. Results: Twenty-five percent of patients worked at the time of completion of the questionnaire. Eighty percent of those patients were working before and after the transplant, $20 \%$ - only after transplantation $(\mathrm{p}<0.05)$. A different job position at a new workplace had $47.8 \%$ of patients, $34.8 \%$ of them had the same job position at the same work place as they had had before, $63.4 \%$ of the heart transplant respondents were pensioners. Eighty-two percent of patients had a certificate with a designated degree of disability - among them: $69 \%$ had a certificate for a significant degree of disability, $22 \%$ - for a moderate degree of disability. Among those surveyed, $52.5 \%$ said that their financial situation had not changed whereas $34.5 \%$ of those surveyed reported a change for the worse. Thirty-seven percent of respondents reported changes in family relationships. Seventy-seven percent reported that they received help from family members, as compared with $19 \%$ who did not. Conclusions: Only $25.3 \%$ of the patients treated at the Silesian Centre for Heart Diseases after heart transplant are employed and it is one of the lowest employment rates in this category of patients in Europe. One third of working patients have the same work place as they had before their operation. Heart transplant is a cause of changes in family relationships. Most often family bonds are strengthened but sometimes family members become nervous, impatient and unwilling to talk about the transplant.
\end{abstract}

Key words: Work, Heart transplant, Social activity, Employment, Family

Received: August 3, 2014. Accepted: December 18, 2014.

Corresponding author: U. Marcinkowska, Silesian Medical University in Katowice, Department of Medicine and Environmental Epidemiology, Jordana 19, 41-808 Zabrze, Poland (e-mail: umarcinkowska@interia.pl). 


\section{INTRODUCTION}

Recovery following a heart transplant implies not only the improvement of a patient's psychophysical condition but also having a good social relationship and being able to perform certain social roles, including occupational activities. In terms of interpersonal relationships - within the family as well as in social contexts of varying levels of closeness - it is necessary to pay attention not only to their presence but also to their quality.

Although work is typically associated with a sense of duty, it may also be considered to be a necessary factor in every human's life because it is a source of self-fulfillment and satisfaction. Moreover, being employed on a position associated with low occupational health risks is crucial, not only in the case of healthy individuals but also in the case of those with poor health conditions, including heart transplant patients. In the long term, those who work following heart transplant suffer less frequently from related diseases or cardiac allograft vasculopathy than those who do not work [1].

Employment is the main source of income for those people because salaries are much higher than income obtainable through pensions or benefits in Poland. Having an income guarantees independence and constitutes a key component of life satisfaction, which is particularly evident in relation to those who have had a heart transplant $[2,3]$.

In 2013 eighty-seven heart transplants were carried out in Poland. Thirty-five of those transplants were done at a 1 centre, the Silesian Centre for Heart Diseases [4]. A heart transplant recipient is effectively given a "second chance", enjoying improved quality of life [5]. In spite of the fact that the average survival rate after transplantation is increasing - currently $79 \%$ of patients survive 1 year and $30 \%$ of them survive 10 years following the surgery [6] - patients need to grapple with many problems, both medical and socio-professional [7] after their transplants. In spite of this, research focuses chiefly on strictly medical aspects of recovery following the heart transplant.
While it is useful to study the quality of professional life following transplant, it is also important to assess this as only one aspect of overall quality of life. As such, the aim of the study is to describe both professional and social activities of patients after heart transplant.

\section{MATERIAL AND METHODS}

Ninety-five heart transplant patients treated at the Silesian Center for Heart Diseases in Zabrze were surveyed, comprising 29 women (30.5\%) and 66 men (69.5\%). Among the respondents, $18 \%$ of them had only primary education, $32.5 \%$ - vocational education, $33.5 \%$ of them had completed high school, and 16\% of them had advanced education. Eighty percent of patients were living in cities. The average age of respondents was 54.3 years old (standard deviation $(\mathrm{SD})=15$ years), the youngest of them was 18 years old and the oldest one -74 years old. The average age of the women was 45 years old, the average age of men was 58 years old ( $\mathrm{p}<0.001)$.

For the entire surveyed group, the average period that elapsed since the heart transplant was 7.1 years ( $\mathrm{SD}=4$ years); the minimum time period from the heart transplant till the time of the interview was 1 year, and the maximum was 18 years.

Out of all the people surveyed, 26 people (27.4\%) were of retirement age (under current retirement legislation this is 60 years old for women and 65 years old for men); the rest of the respondents (72.6\%) were of working age. We designed a questionnaire as a tool for collecting information from patients. Prior to commencing the survey, a pilot questionnaire had been tested with 5 patients to evaluate whether the questions were understandable and would provide responses suitable for meeting the aims of the study. The questionnaire consisted of 2 parts - one of them concerning working activity and the other referring to social activity. The survey was developed in 2 versions: for people who were employed and for those who were unemployed following heart transplant. 
Questions related to employment were included in the version of the questionnaire used to survey the unemployed patients. Furthermore, the following questions on employment were included in both questionnaires: specification of employment situation and source of income; position held before heart transplant and ability to work. Questions related to work experience, employment period, date of re-commencing work after transplant, type of work performed, capability to work and an employer's attitude toward heart transplant workers were included in the questionnaire designed for people employed following their heart transplants.

Questionnaires for both surveyed groups contained a section which consisted of questions relating to post-transplant familial relationships, extra-familial social relationships, and membership in organizations associating former heart transplant patients.

Questionnaires were distributed at the Silesian Center for Heart Diseases outpatient clinic during routine check-up visits, which patients attend periodically following transplant. Only those patients meeting 2 criteria were included in the survey: the age over 18 years old and minimum 1 year elapsed following heart transplant.

Patients were informed of the purpose of the study and they provided written informed consents to participate in the study. The survey was anonymous.

Analyses were conducted using Statistica software version 10.0. Pearson's Chi ${ }^{2}$ and ANOVA tests were used to evaluate differences in the distribution frequency of responses. An $\alpha$ level of 0.05 was used for all statistical tests.

\section{RESULTS}

\section{Assigned job}

Among the respondents, $72.6 \%$ of them were of working age: 18 women (58.6\% of all the surveyed women) and 52 men (77.2\% of all the men surveyed). Twentysix subjects $(27.4 \%)$ were of retirement age, comprising 11 women and 15 men.
Out of the surveyed group, only 24 (25.3\%) of patients worked at the time of completion of the questionnaire. Eighty percent of those patients were working before and after the transplant, $20 \%$ of them - only after transplantation ( $p<0.05$ ). After surgery, $40 \%$ of patients with higher education were employed, as compared to $70 \%$ of them with high school education and $89 \%$ with vocational education $(p=0.001)$. None of the patients with only primary education was employed following heart transplant. Sixty-eight percent of employed patients were living in cities $(\mathrm{p}<0.05)$.

After the transplant, employment situation changed for $61 \%$ of patients who had been working prior to the surgery:

- $8.7 \%$ of the respondents had a new but similar job in the same place of work,

- $4.35 \%$ had a similar job located at a new workplace,

- $47.8 \%$ had a totally different job at a new workplace,

- $34.8 \%$ had the same job at the same work place as prior to the transplant,

- $4.35 \%$ had the same job but at a new work place.

People who had worked before their transplant were asked whether their employers had been supportive at the time of their illness. Employers of $65 \%$ patients had shown their support, which can be classified into 2 forms adapting working conditions to the patient's health status $(61 \%)$, and offering paid leave for the duration of the illness (30.7\%).

Return to work after heart transplantation is an individual matter, which also depends on the results of individual examination. Forty-four percent of respondents returned to work after more than a year following transplant; the remainder returned before 1 year had elapsed following surgery.

The patients who either had worked before or were working after the transplant were satisfied with the number of hours of work required from them (87.5\%); 1 respondent reported too few working hours, and 2 respondents reported that they were expected to work too many hours. 
The respondents were also asked to report their motives for working at their current workplace. Half of them said that they worked in a particular place because they liked their job, $6.2 \%$ of respondents explained this in terms of failing to find employment elsewhere, $18.8 \%$ of respondents did a certain work because it allowed them to earn enough money, and $25 \%$ of patients did their job because they had no other source of income.

In addition, respondents (employed and unemployed) answered the question whether they thought that heart transplant patients in Poland found it hard to find employment. Among patients $66.2 \%$ believed this to be the case, $21 \%$ did not agree, and $13.7 \%$ of respondents had no opinion. Almost $90 \%$ of respondents did not perceive periodic visits to the Silesian Center for Heart Diseases as a problem in getting and/or keeping a job.

\section{Non-profit source of income}

Unemployed patients received either a pension or a retirement pension. Two thirds (63.4\%) of the respondents were pensioners, $28 \%$ of respondents received retirement pensions after their heart transplant. Seventyfive percent of patients receiving the pension worked for at least 10 years before the transplant. However, these patients did not return to work after surgery. Eleven percent of pensioners did not work either before transplantation or after it.

The respondents were asked whether they had been provided with a certificate with a designated degree of disability. Seventy-eight patients $(82 \%)$ reported having such a certificate, 14 patients $(14.8 \%)$ did not have such a certificate, and 3 persons (3.2\%) did not answer this question.

Among those subjects being formally disabled, $69 \%$ had a certificate for a significant degree of disability, $22 \%$ for a moderate degree of disability, $1 \%$ for an insignificant disability, and $8 \%$ declined to answer.

\section{Financial situation}

The financial situation of heart transplant patients is related to their working activity. Respondents were not asked directly about their level of income as this was considered to be a too sensitive issue. Instead, they were asked if and how their financial situation had changed after the transplant. Half of those surveyed said that their financial situation had not changed $(52.5 \%)$, the remainder noticed some changes: $8.5 \%$ reported an improvement in their financial situation whereas $34.5 \%$ of those surveyed reported a change for the worse. No differences were noted in the perception of changes in the financial situations of those employed and those unemployed after transplantation. Nevertheless, there are statistical differences $(p<0.05)$ between the perception of the financial situation of women and men after transplantation. Deterioration of financial situation after transplant was reported by 5 times more men than women.

\section{Family relationships}

The respondents were asked whether their family relationships had changed after the transplant. Thirty-seven percent of respondents reported such a change. They were also asked about the quality of this change. The results are shown in the chart below (Figure 1). There are no statistical differences between the perception of changes in the functioning of the family between men and women.

Subjects were asked whether their relatives were eager to carry out those daily duties on their behalf, which, due to their illness, they could not do. Seventy-seven percent of patients reported that they received such help from family members, as compared with $19 \%$ of them who did not; $4 \%$ of respondents did not answer this question. The vast majority $-86 \%$ of respondents declared that they could count on the assistance of other people in the event of deterioration of their health.

Patients were also asked to indicate how family members reacted to their health problems. Only 71 patients (74\%) answered this question, accounting for the lowest response 


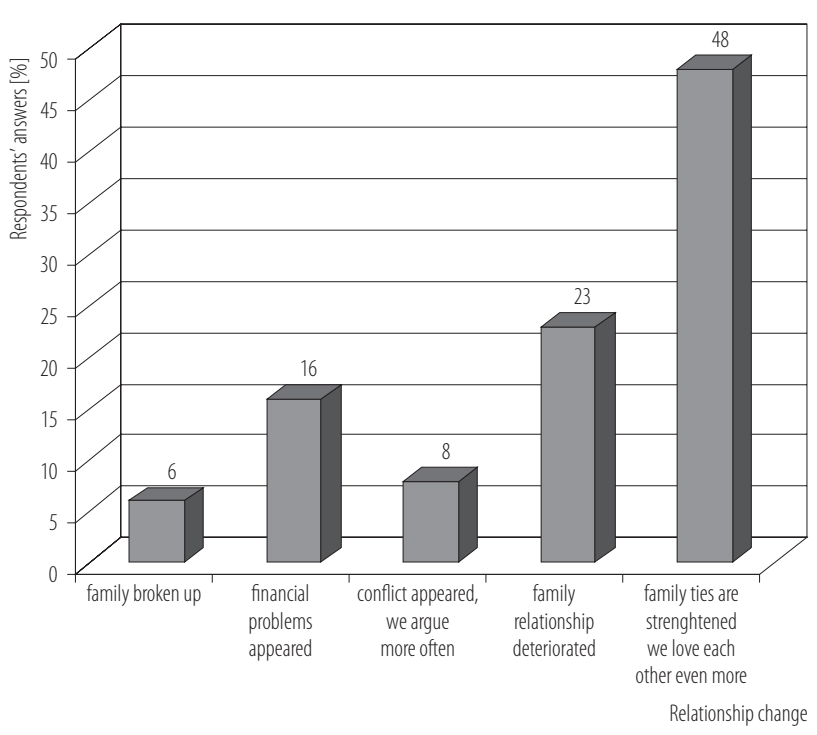

Respondents: $\mathrm{N}=35$, answers of respondents: $\mathrm{N}=52$ (respondents could choose more than 1 answer per question).

Fig. 1. Relationship changes in families, in which one of the members has undergone heart transplant

rate for any question in the survey. The results are shown in the Table 1.

\section{Social relationships}

Social relationships represent another element of social activity. Respondents were asked to answer the question whether and how their social relationships had changed.
Among them, 55.8\% of respondents, independent of their sex, noticed no change; $29.5 \%$ of respondents said that their social life had improved following their heart transplant; $10.5 \%$ of them stated that it had become worse, and $4 \%$ of them declined to answer.

The membership in the Heart Transplant Patient's Association is an important component of the social life of those people. Forty-five of those surveyed were members (47.4\%), both women and men. The average length of membership in the association was 8 years (minimum 2 years, maximum 18 years). Interestingly, over $90 \%$ of the patients were enrolled in the association at the same time as the heart transplant took place (they had been members of the association since the moment of their heart transplant). Respondents' sex did not affect their membership in the association they reported.

\section{DISCUSSION}

The results of the research concerning the activities of people who have undergone heart transplant are varied. In eastern Germany, 22\% [8] of heart recipients returned to work, as compared with $30 \%$ of patients in the whole of Germany [9], 38\% - in Norway [10], 60\% - in Israel [11], and $79 \%$ - in Australia [12]. The factors contributing

Table 1. Patient's family reactions to health problems after a patient's heart transplant

\begin{tabular}{lc}
\hline \multicolumn{1}{c}{ Family reaction } & $\begin{array}{c}\text { Answers }\left(\mathrm{N}=103^{\mathrm{a}}\right) \\
\text { of respondents }(\mathrm{N}=71) \\
{[\%]}\end{array}$ \\
\hline They help me in daily activities & 20.60 \\
They help me out in my household jobs & 26.00 \\
Their whole life has been revolved around my illness & 9.80 \\
They work more so that we could have more money & 10.80 \\
They had to give up their work to take care of me & 1.00 \\
They work less in their profession to take care of me & 1.00 \\
They are upset and impatient & 14.60 \\
They do not want to talk about the illness & 16.50 \\
\hline
\end{tabular}

${ }^{\text {a }}$ Respondents could choose more than 1 answer per question. 
to re-employment are not similar, owing to differences in medical and social conditions in each country.

The social determinants of health of post-transplant patients should be considered in social and health policy, especially with respect to the form of social security, and should be focused on changing the way of thinking of policy-makers in this area. In Polish society, returning to work is undoubtedly a problem for patients that have undergone heart transplant because they tend to be considered as disabled following the surgery. As such they are labeled as unfit for work or as having very limited ability to meet the requirements of employment.

One result of this is that Poland has one of the lowest disabled employment rates (currently it is around 23\%), which corresponds to rates of active employment (27.5\%) [13]. Those who have undergone heart transplant surgery are usually assigned a "significant" or "moderate" level of disability, which are directly related to their supposed inability to work. Our research suggests that $82 \%$ of respondents were assigned disabled status, and $68 \%$ of respondents were declared the "significant" level of disability. Individuals who have had heart transplant may be both declared "disabled" and given a medical certificate of incapacity to work, thereby allowing them to receive a benefit which in 2014 was about 200 euro per month (total disability) or about 152 euro per month (partial disability) [14].

The low value of those benefits causes deterioration in the financial situation of patients, especially for those who worked before transplant. Such changes are viewed more negatively by men, which may be due to the fact that men are typically the breadwinners in families in Poland. Unfortunately, the analysis of social factors relating to reemployment following heart transplants is often neglected in evaluation of the post-operative recovery of heart transplant patients.

The state of health required for an individual to start working is well described in the literature. For example, White-Williams et al. [3] has stated that a long period of unemployment is a major barrier to access employment, regardless of the cause. The necessity to learn new methods of working, to obtain additional qualifications, to undergo re-training (even in the younger age group), and loss of previously attained professional status, make searching for a job even more difficult.

After testing 182 patients between 9-13 years after transplant, Hetzer et al. [8] showed that 51 people $(66 \%)$ received a pension, $17(22 \%)$ of them worked full-time or part-time, and $9(12 \%)$ of them described themselves as "working at home." The research carried out at the Silesian Centre for Heart Diseases, in which the importance of returning to work was investigated in terms of functioning of the transplanted heart, suggests no downward trend with age noted for patients who continued their careers, while in the group of patients who did not work - a clear downward trend was observed.

In our study, the low percentage of people returning to work is related to their demographic status. The majority of people surveyed were middle-aged and older, and with low levels of education. According to several other studies, return to work is easier for both young and better educated people $[1,15,16]$, while subjects' sex or marital status are insignificant.

Although the percentage of people working after heart transplant is low due to continuing post-operative treatment, their general health condition is considerably improved [17]. In our study, we asked if the need to attend medical check-ups impeded employment. The vast majority of respondents did not report any connection between check-ups and their ability to seek or continue employment.

It is believed that many factors that are predictive of reemployment following transplant may already be seen in the pre-operative period. These factors are: duration of unemployment period before surgery, age, level of education, type of insurance and amount of illness benefit received [18-20]. 
Heart transplant recipients represent a special group subjected to enormous biological and psychological pressures. They are burdened with many risks and are more inclined to become ill, so they cannot compete fairly with healthy employees. Moreover, a long break from work due to heart failure has an impact on their ability to earn their living. On the other hand, we should not assume that all or almost all members of this group are unable to work since the patients owning companies are still capable of maintaining their businesses, and many patients report being engaged in various social activities. Stating that all the heart recipients are permanently incapable to work is not only a waste of great potential but it can adversely affect the health of heart transplant recipients.

Social relationships in the case of post-operative heart transplant have not been extensively studied. Perhaps this lack of information is due to the difficulty in observing changes in family and social relations in these populations. Our study indicates the reason for this: respondents are reluctant to answer questions about their family, professional or financial situation. Unquestionably, social bonds are of considerable importance to those who have undergone heart transplant. They are important for the prognosis while waiting for a new heart - thus social isolation coincides with confirmed clinical depression. Tight social bonds are important determining factors in the context of survival and improvements of the health status of heart transplant patients [21].

Social support for patients is also essential following heart transplant. In the broad network of social support, the family is the most important source of support, especially the support provided by the spouse. The research has confirmed that being married extends survival after heart transplant, although it is currently unknown to what degree support from other family members (children, grandchildren) might improve survival [22]. Our study shows that almost $1 / 5$ of patients cannot count on help from their families.

\section{CONCLUSIONS}

Only $25.3 \%$ of patients treated by the Silesian Centre for Heart Diseases after heart transplant are employed and it is one of the lowest employment rates in this category of patients in Europe.

Only $34.8 \%$ of working patients have the same job position at the same workplace as they had before their operation. Maintaining their employment depends on: work before transplantation, level of education and place of residence. Eighty-two percent of the post-operative patients have a certificate of disability, and most often it may curb the possibility of finding a job. The main sources of income for the respondents include health benefits and retirement pensions; nearly $35 \%$ of patients report deterioration of their financial status following surgery.

Heart transplant is a cause of changes in family relationships. Most often family bonds are strengthened but sometimes family members become nervous, impatient and unwilling to talk about the issues related to transplant. Questions concerning the private life of transplant patients are perceived by them as difficult and confusing and, if questions refer to family reactions to health problems after a patient's heart transplant, they often remain unanswered. The reasons for this should be explained in further scientific research because social support is currently insufficient for this group of patients.

\section{REFERENCES}

1. White-Williams C, Wang E, Rybarczyk B, Grady KL. Factors associated with work status at 5 and 10 years after heart transplantation. Clin Transplant. 2011;25:E599-605, http://dx.doi.org/10.1111/j.1399-0012.2011.01507.x.

2. Petrucci L, Ricotti S, Michelini I, Vitul P, Oggionni T, Cascina A, et al. Return to work after thoracic organ transplantation in a clinically-stable population. Eur J Heart Fail. 2007;9:1112-9, http://dx.doi.org/10.1016/j.ejheart.2007.08.002.

3. White-Williams C, Jalowiec A, Grady K. Who returns to work after heart transplantation? J Heart Lung Transplant. 
2005;24(12):2255-61, http://dx.doi.org/10.1016/j.healun.20 05.08.006.

4. Antoszkiewicz K, Czerwiński J. [Donation and transplantation of organs in Poland in 2013]. Poltransplant. Inform Bull. 2014;1(22):8-22. Polish.

5. Czyżewski $Ł$, Torba K, Jasińska M, Religa G. Comparative analysis of the quality of life for patients prior to and after heart transplantation. Ann Transplant. 2014;17(19):288-94.

6. Christie JD, Edwards LB, Kucheryavaya AJ, Benden C, Dipchand AI, Dobbels F, et al. The registry of the International Society for Heart and Lung Transplantation: 29th adult lung and heart-lung transplant report - 2012. J Heart Lung Transplant. 2012 Oct;31(10):1052-64, http://dx.doi.org/10. 1016/j.healun.2012.08.004.

7. Marcinkowska U, Jośko J, Ciszewska P, Kulig M, Wojniak E, Wesołowski B. [Chosen aspects of everyday functioning persons after heart transplants]. Probl Hig Epidemiol. 2010;91(2):263-7. Polish.

8. Hetzer R, Albert W, Hummel M, Pasic M, Loebe M, Warnecke $\mathrm{H}$, et al. Status of patients presently living 9 to 13 years after orthotopic heart transplantation. Ann Thorac Surg. 1997;64(6):1661-8, http://dx.doi.org/10.1016/ S0003-4975(97)01091-6.

9. Kristen AV, Ammon K, Koch A, Dösch AO, Erbel C, Celik S, et al. Return to work after heart transplantation: Discrepancy with subjective work ability. Transplantation. 2009; 87:1001-5, http://dx.doi.org/10.1097/TP.0b013e31819ca1ee.

10. Sivertsen B, Relbo A, Gullestad L, Hellesvik M, Grov I, Andreassen A, et al. [Self-assessed health and psychological symptoms after heart transplantation]. Tidsskr Nor Laegeforen. 2007;127(24):3198-201. Norwegian.

11. Inspector Y, Kutz I, David D. Another person's heart: Magical and rational thinking in the psychological adaptation to heart transplantation. Isr J Psychiatry Relat Sci. 2004;41(3):161-73.

12. Jones BM, Taylor F, Downs K, Spratt P. Longitudinal study of quality of life and psychological adjustment after cardiac transplantation. Med J Aust. 1992;157:24-6.
13. [The Government Plenipotentiary for Disabled People. Labour market] [Internet]. Warszawa: [The Plenipotentiary] [cited 2014 Jan 20]. Available from: http://www.niepelnosprawni. gov.pl/niepelnosprawnosc-w-liczbach-/rynek-pracy. Polish.

14. [The Social Insurance Institution. Contributions and benefits] [Internet]. Warszawa: [The Institution] [cited 2014 Oct 26]. Available from: http://www.zus.pl/default.asp?p $\% 20$ $=\% 201 \&$ id $\% 20=\% 2052$. Polish.

15. Rosenblum DS, Rosen MI, Pine Z, Rosen S, Borg-Stein J. Health status and quality of life following cardiac transplantation. Arch Phys Med Rehabil. 1993;74:490, http://dx.doi. org/10.1016/0003-9993(93)90111-M.

16. Paris W, Woodbury A, Thompson S, Levick M, Nothegger S, Hutkin-Slade L, et al. Social rehabilitation and return to work after cardiac transplantation - A multicenter survey. Transplantation. 1992;53:433, http://dx.doi.org/10.1097/0000 7890-199202010-00032.

17. Pocock SJ, Henderson RA, Seed P, Treasure T, Hampton JR. Quality of life, employment status, and anginal symptoms after coronary angioplasty or bypass surgery. 3-year followup in the Randomized Intervention Treatment of Angina (RITA) trial. Circulation. 1996;94:135-42, http://dx.doi. org/10.1161/01.CIR.94.2.135.

18. Bodsford AL. Review of literature on heart transplant recipients' return to work: Predictors and outcomes. Soc Work Health Care. 1995;21:19-39, http://dx.doi.org/10. 1300/J010v21n02_02.

19. Meister ND, McAleer MJ, Meister JS, Riley JE, Copeland JG. Returning to work after heart transplantation. J Heart Transplant. 1986;5:154-61.

20. Paris W, Woodbury A, Thompson S, Levick M, Nothegger S, Arbuckle P, et al. Returning to work after heart transplantation. J Heart Lung Transplant. 1993;12:46-53.

21. Spaderna H, Mendell NR, Zahn D, Wang Y, Kahn J, Smits JM, et al. Social isolation and depression predict 12-month outcomes in the "waiting for a new heart study”. J Heart Lung Transplant. 2010;29(3):247-54, http:// dx.doi.org/10.1016/j.healun.2009.07.018. 
22. Tam V, Arnaoutakis GJ, George TJ, Russell SD, Merlo CA, Conte JV, et al. Marital status improves survival after orthotopic heart transplantation. J Heart Lung Transplant. 2011;30(12):1389-94, http://dx.doi.org/10.1016/j.healun.2011.07.020.

This work is available in Open Access model and licensed under a Creative Commons Attribution-NonCommercial 3.0 Poland License - http://creativecommons.org/ licenses/by-nc/3.0/pl/deed.en. 